\title{
(2) OPEN ACCESS \\ Impaired fertility in men diagnosed with inflammatory arthritis: results of a large multicentre study (iFAME-Fertility)
}

\author{
Luis Fernando Perez-Garcia $\odot,{ }^{1}$ Esther Röder, ${ }^{1}$ Robbert I Goekoop $\odot,{ }^{2}$ \\ Johanna M W Hazes, ${ }^{1}$ Marc R Kok $\odot,{ }^{3}$ Hieronymus T W Smeele $\odot,{ }^{1}$ \\ Ilja Tchetverikov, ${ }^{4}$ Annette H M van der Helm-van Mil $\odot{ }^{1,5}$ Jos H van der Kaap, ${ }^{1,6}$ \\ Petra Kok, ${ }^{7}$ Bouwe P Krijthe, ${ }^{1,8}$ Radboud J E M Dolhain ${ }^{1}$
}

\begin{abstract}
Handling editor Josef $S$
Smolen

- Additional online supplemental material is published online only. To view, please visit the journal online (http://dx.doi.org/10.1136/ annrheumdis-2021-220709).
\end{abstract}

For numbered affiliations see end of article.

\section{Correspondence to}

Dr Luis Fernando Perez-Garcia, Rheumatology, Erasmus Medical Center, Rotterdam 3015 GD, The Netherlands:

I.perez@erasmusmc.n

EULAR 21 Virtual Congress

Received 3 May 2021

Accepted 9 July 2021

Published Online First

9 August 2021
Check for updates

(C) Author(s) (or their employer(s)) 2021. Re-use permitted under CC BY-NC. No commercial re-use. See rights and permissions. Published by BMJ.

To cite: Perez-Garcia LF,

Röder E, Goekoop RJ,

et al. Ann Rheum Dis

2021:80:1545-1552.

\section{ABSTRACT}

Objectives The impact of inflammatory arthritis (IA) on male fertility remains unexplored. Our objective was to evaluate the impact of IA on several male fertility outcomes; fertility rate (number of biological children per man), family planning, childlessness and fertility problems.

Methods We performed a multicentre cross-sectional study (iFAME-Fertility). Men with IA 40 years or older who indicated that their family size was complete were invited to participate. Participants completed a questionnaire that included demographic, medical and fertility-related questions. To analyse the impact of IA on fertility rate, patients were divided into groups according to the age at the time of their diagnosis: $\leq 30$ years (before the peak of reproductive age), between 31 and 40 years (during the peak) and $\geq 41$ years (after the peak).

Results In total 628 participants diagnosed with IA were included. Men diagnosed $\leq 30$ years had a lower mean number of children (1.32 (SD 1.14)) than men diagnosed between 31 and 40 years (1.60 (SD 1.35)) and men diagnosed $\geq 41$ years (1.88 (SD 1.14)). This was statistically significant $(p=0.0004)$. The percentages of men diagnosed $\leq 30$ and 31-40 years who were involuntary childless $(12.03 \%$ vs $10.34 \%$ vs $3.98 \%$, $\mathrm{p}=0.001)$ and who reported having received medical evaluations for fertility problems $(20.61 \%, 20.69 \%$ and $11.36 \%, p=0.027)$ were statistically significant higher than men diagnosed $\geq 41$ years.

Conclusions This is the first study that shows that IA can impair male fertility. Men diagnosed with IA before and during the peak of reproductive age had a lower fertility rate, higher childlessness rate and more fertility problems. Increased awareness and more research into the causes behind this association are urgently needed.

\section{INTRODUCTION}

Spondyloarthritis $(\mathrm{SpA})$ and rheumatoid arthritis (RA) are frequent causes of inflammatory arthritis (IA) that can affect men before or during the peak of their reproductive age. ${ }^{1-4}$ Even though IA is associated with male infertility, erectile dysfunction and hypogonadism ${ }^{5} 6$ the impact of IA on male fertility remains largely unexplored. This is even more striking if we consider that several frequently prescribed anti-rheumatic drugs have

\section{Key messages}

What is already known about this subject?

- Inflammatory arthritis $(\mathrm{IA})$ is associated with male infertility, erectile dysfunction and hypogonadism.

What does this study add?

- The diagnosis of IA before or during the peak of the male reproductive age was associated with a lower fertility rate, higher rates of involuntary childlessness and fertility problems.

How might this impact on clinical practice or future developments?

- Rheumatologists should be aware that IA and/ or the pharmacological treatment associated with IA may impair male fertility.

- Multiple biological and non-biological mechanisms can be responsible for this association and more research is urgently needed.

been associated with reversible or irreversible testicular toxicity. ${ }^{7}$

The majority of people aspire to have children and it is known that men desire parenthood as much as women do. ${ }^{8-10}$ Nonetheless, the impact of IA on one of the most important markers of fertility, the male fertility rate (total number of children per man), ${ }^{11-13}$ has never been studied before.

Childbearing decisions and reproductive potential are strongly influenced by multiple psychosocial, demographic and biological factors. ${ }^{9} 14$ Furthermore, it has been demonstrated that men diagnosed with chronic diseases are exposed to additional factors that have an effect on their childbearing decisions and their reproductive potential. $^{1516}$

In women diagnosed with IA, several factors related to IA have been associated with lower fertility rates. ${ }^{17-19}$ It can be expected that some of these factors could also influence the fertility rate of men diagnosed with IA, such as impaired sexual function, lower intercourse frequency, deciding not to have a family or to have smaller 
families due to concerns about the impact of IA or antirheumatic treatment.

Therefore, we aimed to evaluate the impact of IA on relevant markers of male fertility. Our primary objective was to compare the fertility rate of men diagnosed with IA based on their age at diagnosis. Additionally, we compared the fertility rate of men diagnosed with IA with the general male population of the Netherlands. To further evaluate the impact of IA on male fertility, as secondary objectives we compared the total number of pregnancies per man, desired family size (family planning), the proportion of childless men and fertility outcomes based on the results from medical evaluations for fertility problems.

\section{METHODS}

\section{Study design and patient selection}

We conducted a multicentre cross-sectional study in eight Dutch hospitals (iFAME (Inflammunity and Fertility in Men)-Fertility study). In the Netherlands, most men become a father between the age of 30 and 40 years and this period is considered to be the peak of reproductive age. ${ }^{20}$ Therefore, men who were diagnosed with IA based on the expert opinion of their rheumatologists (RA, juvenile idiopathic arthritis (JIA) and SpA (ankylosing spondylitis (AS), psoriatic arthritis (PsA), reactive arthritis, enteropathic arthritis), who at the time of inclusion were 40 years or older and who indicated that their 'family size' was completed were included. Men who were still planning on having biological children in the future were excluded.

To evaluate the impact of IA on male fertility we considered the age at diagnosis of IA and divided participants into three study groups: diagnosis $\leq 30$ years (before the peak of reproductive age), diagnosis between 31 and 40 years (during the peak of reproductive age) and diagnosis $\geq 41$ years (after the peak reproductive age).

We estimated the mean number of children number per men without IA in their reproductive lifespan at 1.7 (SD: 1.0) and estimated a mean number of 1.4 children as significantly different. Using data simulation that accounted for dispersion and under-dispersion, to reject the null hypothesis with a $80 \%$ power (alpha $=0.05$; two sided), it was estimated that 548 men were needed to be included in the study $(n=137, n=137$ and $n=274$ per group, respectively).

\section{Data collection}

A self-reported questionnaire developed for this study was used. The design of this questionnaire was based on the 'fertility experiences questionnaire (FEQ)'. The FEQ was validated in women with subfertility and when compared with medical records it was proven to be over $90 \%$ sensitive for fertility outcomes. ${ }^{21}$ In addition, we adapted the questionnaire to our population using previous questionnaires that have evaluated fertility outcomes in male kidney transplant recipients ${ }^{22}$ and in women with rheumatic diseases. ${ }^{23} 24$ Our questionnaire was divided into four sections: general demographic information, medical history, family planning and fertility outcomes (online supplemental 1). The digital version of the questionnaire that was distributed to participants was built using the survey software GemsTracker/ LimeSurvey (LimeSurvey, Hamburg, Germany).

Men who fulfilled the inclusion criteria of being 40 years or older and diagnosed with IA were invited to participate in the study. These men received a letter from their hospital that included information about the study. To ensure the protection of privacy data, the letter included a personalised link to complete the digital questionnaire. To increase the number of responders, a second letter was sent to all non-responders.

Our primary outcome, the male fertility rate, was calculated using the answers to the question 'How many biological children did you have?'. This is a validated method that has been used to evaluate fertility. For secondary outcomes, other collected data include, but are not limited to, total number of pregnancies, desired family size, satisfaction with final family size and relevant medical history regarding fertility and pregnancy outcomes. A pregnancy was defined as 'any positive pregnancy test (even if it did not result in a live born child)' and time to pregnancy (TTP) was determined with the answers provided to the question 'How many months did it take for your partner to get pregnant?'.

A Likert scale questionnaire (scale ranging from completely disagree (0) to completely agree (10)) was used to evaluate the impact of IA on family planning/desired number of children.

\section{Statistical analysis}

Comparisons between the three groups and between the groups and the general population were tested. Categorical variables were presented as number (percentage), and continuous variables are reported as mean $\pm S D$ or median $\pm I Q R$, as appropriate. Continuous variables were compared using a one-way analysis of variance, Tukey post hoc test, paired t-test and Wilcoxon rank. Categorical variables were compared using $\chi^{2}$ tests and Fisher's exact tests. To control for confounders, multivariate regression model (analysis of covariance) was used. All potential confounders were fitted into the model. The level of significance was set as a two-tailed $\mathrm{p} \leq 0.05$, and statistical analyses were completed using Stata V.15 (StataCorp).

\section{Patient and public involvement}

Six male patients diagnosed with IA and who are active members of the research advisory board from the Department of Rheumatology of the Erasmus University Medical Center were involved in the design of the questionnaire and the invitation letter. We carefully assessed the burden on participating patients. We intend to share the results to participating patients and will appropriately disseminate the results.

\section{RESULTS}

Between September 2019 and January 2021, a total of 1841 men were invited to participate in the study. All hospitals invited men from the three study groups using a 1:1:2 ratio until the necessary number of patients per group to achieve statistical power was reached. In total, 628 men agreed to participate (response rate of $34.1 \%$ ). A detailed description of the demographics characteristics of these men is presented in table 1. Due to current privacy regulations that are applicable in the Netherlands, it was not possible to describe the demographic characteristics of the non-responders.

\section{Total number of biological children (fertility rate)}

Men diagnosed $\leq 30$ years had a lower number of children $(1.32$ (SD 1.14)) than men diagnosed between 31 and 40 years $(1.56$ (SD 1.27)) and men diagnosed $\geq 41$ years (1.88 (SD 1.14)) (see figure 1 ). There was a statistically significant difference between groups $(p=0.0004)$. The total number of children was statistically significant lower in men diagnosed $<30$ years and in men diagnosed $31-40$ years compared with men diagnosed $>41$ years $(p<0.001$ and $p=0.020$, respectively). The difference between men diagnosed $<30$ and $31-40$ years was not statistically significant $(\mathrm{p}=0.264)$. 
Table 1 Demographic characteristics

\begin{tabular}{|c|c|c|c|c|c|}
\hline & $\begin{array}{l}\text { All patients } \\
(\mathrm{N}=628)\end{array}$ & $\begin{array}{l}\text { IA diagnosed } \\
\leq 30 \text { years } \\
(\mathrm{N}=137)\end{array}$ & $\begin{array}{l}\text { IA diagnosed } \\
31-40 \text { years } \\
(\mathrm{N}=149)\end{array}$ & $\begin{array}{l}\text { IA diagnosed } \\
\geq 41 \text { years } \\
(\mathrm{N}=342)\end{array}$ & $P$ value \\
\hline \multicolumn{6}{|l|}{ General information } \\
\hline Age at inclusion in the study, mean (SD) & $57.17(9.98)$ & $53.01(9.96)^{*}$ & $52.76(7.35)^{*}$ & $61.06(9.47)$ & 0.001 \\
\hline Born in the Netherlands, $\mathrm{n}(\%)$ & $531(94.48)$ & $117(92.13)$ & $132(94.96)$ & $277(95.19)$ & 0.143 \\
\hline $\begin{array}{l}\text { Education } \\
\text { Bachelor degree or higher, } \mathrm{n}(\%)\end{array}$ & $223(35.51)$ & $61(44.53)^{*}$ & $51(34.23)$ & $111(32.46)$ & 0.048 \\
\hline Currently in a relationship, $\mathrm{n}(\%)$ & $423(67.36)$ & $89(64.96)$ & $100(67.11)$ & $234(68.42)$ & 0.765 \\
\hline \multicolumn{6}{|l|}{ Inflammatory arthritis } \\
\hline \multicolumn{6}{|l|}{ Diagnosis, $\mathrm{n}(\%)$} \\
\hline RA & $297(47.29)$ & $42(30.66)^{*} \dagger$ & $67(44.97)$ & $188(55.32)$ & 0.001 \\
\hline JIA & $10(1.59)$ & $10(6.45)$ & 0 & 0 & - \\
\hline SpA (incl. PsA) & $320(50.96)$ & $90(65.69)^{*}$ & $83(55.70)$ & $147(42.98)$ & 0.001 \\
\hline Age at diagnosis, mean (SD) & $41.30(13.08)$ & $23.76(6.17)^{*} \dagger$ & $36.52(2.48)^{*}$ & $51.25(7.77)$ & 0.001 \\
\hline Disease duration, mean (SD) & $15.89(11.88)$ & $29.51(11.30)^{*} \dagger$ & $16.30(8.29)^{*}$ & $9.68(7.77)$ & 0.001 \\
\hline $\begin{array}{l}\text { Concerning your IA, have you ever received information about } \\
\text { your desire to have children? Yes, } n(\%)\end{array}$ & $139(22.13)$ & $45(33.83)^{*}$ & $36(24.66)^{*}$ & $37(11.31)$ & 0.001 \\
\hline \multicolumn{6}{|l|}{ Comorbidities } \\
\hline Type 2 diabetes mellitus, $\mathrm{n}(\%)$ & $54(8.60)$ & $13(9.49)$ & $10(6.71)$ & $31(9.06)$ & 0.635 \\
\hline Cardiovascular disease, $¥ \mathrm{n}(\%)$ & $98(15.61)$ & $17(12.41)$ & $13(8.72)^{*}$ & $68(19.88)$ & 0.006 \\
\hline Inflammatory bowel disease, $\mathrm{n}(\%)$ & $21(3.34)$ & $5(3.65)$ & $7(5.04)$ & $7(2.05)$ & 0.278 \\
\hline Urogenital comorbidities, § n (\%) & $27(4.30)$ & $6(4.38)$ & $3(2.01)$ & $18(5.26)$ & 0.264 \\
\hline
\end{tabular}

${ }^{*} \mathrm{P} \leq 0.05$ compared with those diagnosed age $\geq 41$ years.

$\mathrm{t} \mathrm{p} \leq 0.05$ compared with those diagnosed age $\geq 31-40$ years.

¥Arterial hypertension, angina pectoris, myocardial infarction, heart failure, stroke, peripheral vascular disease and dyslipidaemia.

§Urogenital infection, sexually transmitted disease, cryptorchidism, varicocele, testicular torsion, epididymitis, prostatitis, inguinal hernia, urogenital surgery, urogenital trauma and exposure to

chemicals or radiation that can result in DNA damage.

$I A$, inflammatory arthritis; JIA, juvenile idiopathic arthritis; PsA, psoriatic arthritis ; RA, rheumatoid arthritis; SpA, spondyloarthritis.

After adjusting for potential confounders (current age, education level, history of cardiovascular disease, diagnosis of infertility in partner and diagnosis of RA, JIA and SpA) and considering the total number of children of men diagnosed $\geq 41$ years as our reference group, we observed a statistically significant negative effect on the

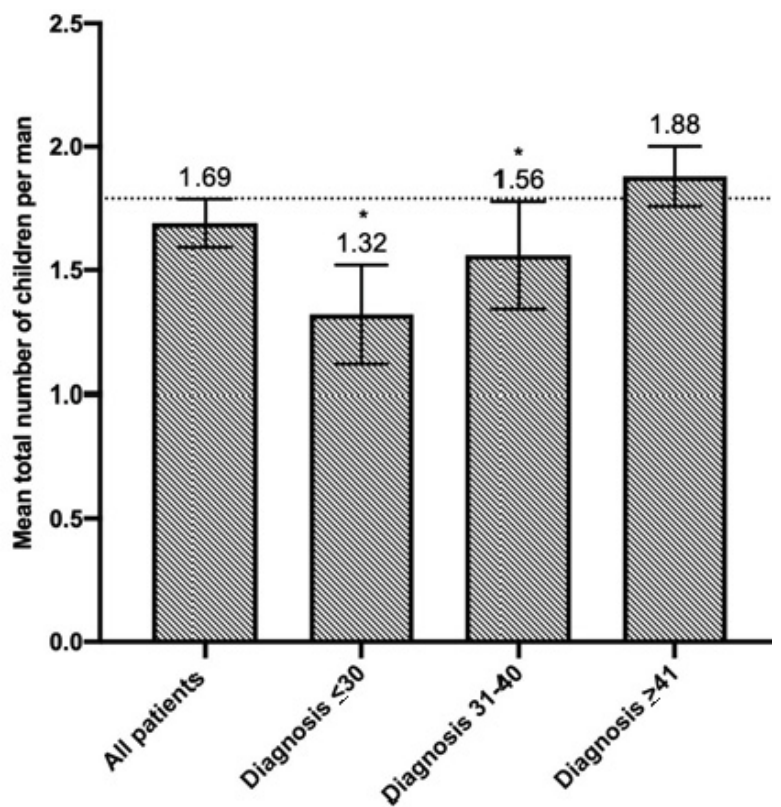

Figure 1 Mean total number of children per man for all participants and per group. Error bars represent $95 \% \mathrm{Cl}$. The dotted line represents the mean number of children per man for men older than 40 years in the Netherlands. *Statistically significantly different compared with men diagnosed $\geq 41$ years. total number of children of men diagnosed $\leq 30$ years $(p=0.002)$ (see table 2). Furthermore, the total number of children per disease was not statistically significant between diseases.

Lastly, we compared the fertility rate of the study groups with the fertility rate of all men living in the Netherlands who at the time of our last inclusion were 40 years or older (1.79, Statistics Netherlands (CBS),personal communication, 18 August 2020). Compared with the fertility rate of men $\geq 40$ years from the general population, the fertility rate of men diagnosed $\leq 30$ and $31-40$ years was statistically significant lower $(1.32, p=0.001$ and $1.56 p=0.03$, respectively). The fertility rateof men diagnosed $\geq 41$ years was not statistically significant different $(1.88, \mathrm{p}=0.128)$.

\section{Total number of pregnancies per man}

In contrast to the fertility rate, where only live births are taken into account, the total number of pregnancies per man includes any positive pregnancy test independent of the final pregnancy outcome. Men diagnosed $\leq 30$ years had a lower total number of pregnancies (1.45 (SD 1.37)) than men diagnosed between 31 and 40 years (1.73 (SD 1.69)) and men diagnosed $\geq 41$ years (1.98 (SD 1.45)). There was a statistically significant difference between groups $(p=0.0023)$. The total number of pregnancies was statistically significant lower in men diagnosed $\leq 30$ years compared with men diagnosed $\geq 41$ years $(p=0.002)$. There were no statistically significant differences between men diagnosed $<30$ and $31-40$ years $(p=0.261)$ and between men diagnosed $31-40$ and $\geq 41$ years $(p=0.219)$.

\section{Childlessness}

In the Netherlands, the percentage of childless men ranges between $20 \%$ and $25 \% .{ }^{25}$ In total, 143 men $(22.27 \%)$ were childless most of whom were voluntary childless $(n=99(69.23 \%))$. 
Table 2 Analysis of covariance: effect of dichotomised age at diagnosis of IA (based on our study groups) on total number of children per man and considering the total number of children of men diagnosed $\geq 41$ years as our reference group

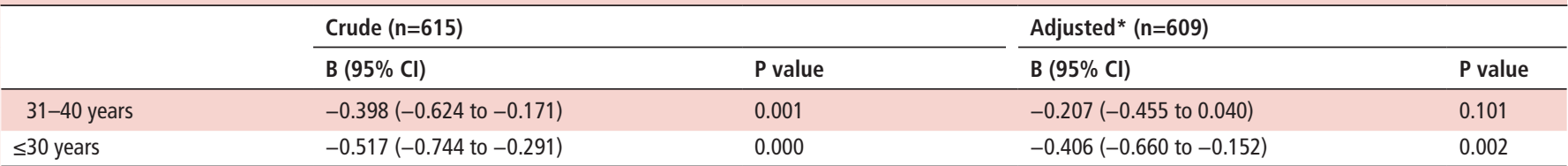

*Adjusted for confounders (age at inclusion in the study, education level, cardiovascular disease, diagnosis of infertility in partner and diagnosis of RA, JIA and SpA).

IA, inflammatory arthritis; JIA, juvenile idiopathic arthritis; RA, rheumatoid arthritis; SpA, spondyloarthritis.

The percentage of childless men was significantly higher in men diagnosed $\leq 30$ years $(n=45(33.83 \%))$ and in men diagnosed $31-40$ years $(n=39(26.90 \%))$ compared with men diagnosed $\geq 41$ years $(n=59(17.25 \%), p=0.001)$.

In addition, we compared the percentages of voluntary and involuntary childlessness between the groups. The proportion of men who were voluntary childless was statistically significant different (29 (24.79), 24 (18.32) and 46 (14.64), $\mathrm{p}=0.048)$. The proportion of men who were involuntary childless was also statistically significant different between our groups (16 (12.03\%), 15 $(10.34 \%)$ and $13(3.98 \%), p=0.001)$. Among childless men, the percentage of men who were involuntary childless was statistically significant between our groups $(35.56 \%$ vs $38.46 \%$ vs $22.03 \%, \mathrm{p}=0.046)$.

\section{Desired number of children and family planning}

The desired number of children was not statistically different between the three groups (1.75 (SD 1.32) vs 1.86 (SD 1.22) vs 2.03 (SD 1.18), $\mathrm{p}=0.083$ ). Statistically significant more men diagnosed $\leq 31$ years and 31-40 years reported feeling unsatisfied with their final number of children than men diagnosed $\geq 41$ years $(n=22(16.67 \%), n=14(9.66 \%)$ and $n=18(5.50 \%)$, $\mathrm{p}=0.010)$. Approximately one-third of these men reported that the diagnosis of IA and/or the medical treatment associated with it, were the main reason to have less children $31 \%$ and $28 \%$, respectively).

The difference between desired and final number of children was significantly wider in men diagnosed $\leq 30$ years $(0.41$ (SD $0.98)$ ) compared with men diagnosed $\geq 41$ years $(0.14$ (SD $0.77), p=0.003)$. Compared with men diagnosed $31-40$ years, the difference between desired and final number of children was not statistically significant different $(0.29$ (SD 0.74), $\mathrm{p}=0.181)$ (see figure 2).

Furthermore, to analyse the impact of IA on the fertility rate of men who wanted to become a father, we conducted a subgroup analysis where all men who were voluntary childless were excluded (see table 3 ).

Using a Likert scale questionnaire, a significant negative effect of IA on family planning was reported by men diagnosed $\leq 30$ and 31-40 years (see figure 3). Statements such as 'I was concerned that my medications would harm my child' or 'I was afraid that my child would get the same disease as me' were graded with a significantly higher degree of agreement among men diagnosed $\leq 30$ and $31-40$ years.

Moreover, among men who remained voluntary childless, the statement 'My disease reduced my desire to have children' was graded higher by men diagnosed $\leq 30$ years $(5.93(2.42)$ ) than by men diagnosed $31-40$ years $(3.73(1.91))$ and by men diagnosed $\geq 41$ years $(1.35(1.14))$. This was statistically significant different $(p=0.001)$. Among men who remained involuntary childless and compared with men diagnosed $\geq 41$ years, the statement 'Stopping of weaning off my medication because of my desire to have children was not possible because my disease was too active' was graded statistically significant higher by men diagnosed $\leq 30$ years (see figure 4 ).

\section{Fertility}

Statistically significantly more men diagnosed $\leq 30$ and $31-40$ years reported having received medical evaluations for fertility problems, compared with men diagnosed $\geq 41$ years $(n=27$ (20.61\%), $\mathrm{n}=30 \quad(20.69 \%)$ and $\mathrm{n}=35$ (11.36\%), $\mathrm{p}=0.027)$ and ultimately receiving a diagnosis of low sperm quality $(n=9$ (6.57\%), $n=12(8.05 \%)$ and $n=12(3.51 \%), p=0.086)$. Statistically significant more female partners of men diagnosed $\leq 30$ years received a diagnosis of infertility secondary to an unknown cause (see table 4).

In men who achieved a pregnancy, TTP was statistically significant higher in men diagnosed 31-40 years (6.74 (SD 11.12) months) compared with men diagnosed $\leq 41$ years $(4.77$ (SD 8.47) months, $\mathrm{p}=0.045)$ and not statistically significantly different when compared with men diagnosed $\leq 30$ years $(5.69$ (SD 10.93), $\mathrm{p}=0.623$ ).

\section{DISCUSSION}

Our study is the first of its kind to demonstrate that IA can significantly impair male fertility. The diagnosis of IA before or during the peak of the male reproductive age was associated with a lower fertility rate, lower number of pregnancies, higher rates of involuntary childlessness and fertility problems.

\section{- Desired number of children per man}

\section{- Final number of children per man}

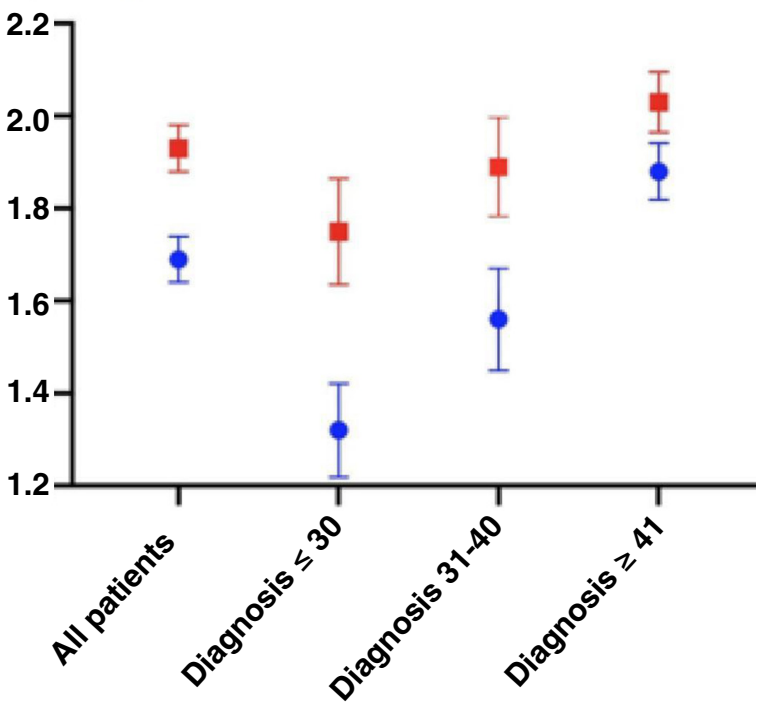

Figure 2 Comparison of the desired and final number of children per man for all participants and per group (mean $+95 \% \mathrm{Cl}$ ). 
Table 3 Analysis of covariance: effect of dichotomised age at diagnosis of IA (based on our study groups) on total number of children per man (excluding men who were voluntary childless) and considering the total number of children of men diagnosed $\geq 41$ years as our reference group

\begin{tabular}{|c|c|c|c|c|}
\hline & \multicolumn{2}{|l|}{ Crude $(n=507)$} & \multicolumn{2}{|l|}{ Adjusted* $(n=501)$} \\
\hline & B $(95 \% \mathrm{Cl})$ & $P$ value & B $(95 \% \mathrm{Cl})$ & $P$ value \\
\hline $31-40$ years & $-0.279(-0.501$ to -0.058$)$ & 0.013 & $-0.205(-0.434$ to 0.022$)$ & 0.078 \\
\hline$\leq 30$ years & $-0.474(-0.702$ to -0.246$)$ & 0.000 & $-0.352(-0.550$ to -0.113$)$ & 0.004 \\
\hline
\end{tabular}

*Adjusted for confounders (age at inclusion in the study, education level, cardiovascular disease, diagnosis of infertility in partner and diagnosis of RA, JIA and SpA).

IA, inflammatory arthritis; JIA, juvenile idiopathic arthritis; RA, rheumatoid arthritis; SpA, spondyloarthritis.

Respecting family planning we observed that the number of desired children per man was lower in men diagnosed before and during the peak of male reproductive age. Nonetheless, this was not statistically significant different between our groups and it was similar to the number of desired children per man reported for the general population of the Netherlands (1.81-2.29). ${ }^{26}$ Conversely, the difference between the desired and final number of children was significantly larger in men diagnosed before and during the reproductive age, indicating that the lower fertility rates are primarily affected by reduced fertility potential and not by a reduced desire for parenthood.

In this regard, men diagnosed with IA before and during the peak of their reproductive age were two times more likely to remain involuntary childless (12\% and $10 \%)$. To put this into perspective, it is estimated that around $4 \%$ of healthy couples who want children remain involuntary childless. ${ }^{27}$

Moreover, it was shown that the diagnosis of IA may have a major impact on family planning. Not only did IA significantly reduce the desire to have children of men diagnosed before and during the peak of reproductive age who remained voluntary childless but also concerns or difficulties with regard to pharmacological treatment were larger in men diagnosed with IA before the peak of reproductive age who remained involuntary childless.

Lastly, the diagnosis of IA before and during the peak of reproductive age is associated with male fertility problems. These men were twice as likely to be evaluated for fertility problems and being subsequently diagnosed with abnormal sperm quality. In

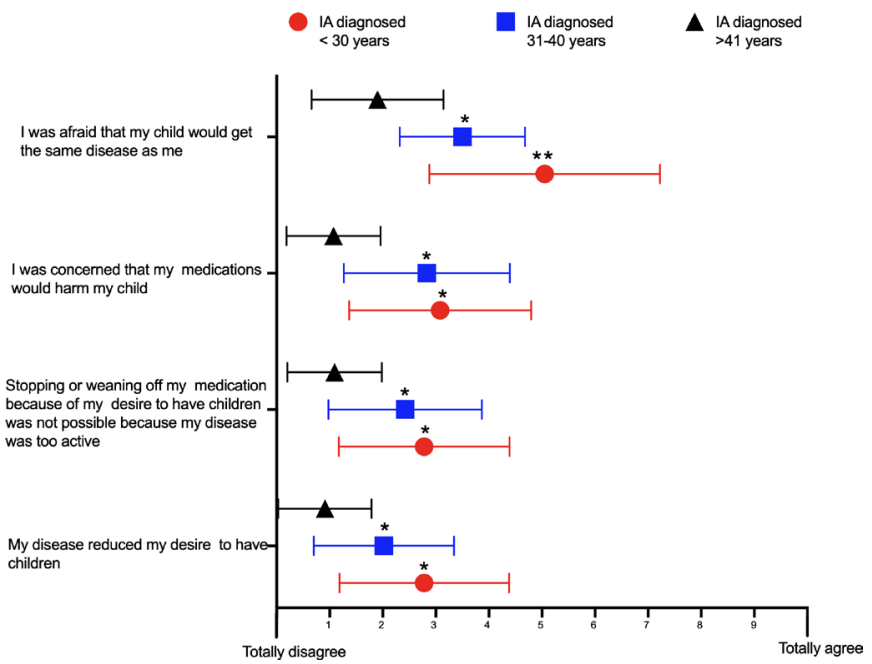

Figure 3 Likert scale questionnaire regarding the influence of la on family planning. men answered the questions using a 0-10 scale where 0 meant 'totally disagree' and 10 'totally agree' (mean with SD) ${ }^{*} \mathrm{P} \leq 0.05$ compared with those diagnosed age $\geq 41$ years. ${ }^{*} \mathrm{*} \leq 0.05$ compared with those diagnosed $31-40$ years and $\geq 41$ years. IA, inflammatory arthritis. this regard, it has been estimated that abnormal sperm quality affects $2 \%$ of adult men. ${ }^{28}$ This estimation is considerably lower compared with the $6.5 \%$ and $8 \%$ reported by men diagnosed with IA before and during the peak of reproductive age.

Similar to our results, Uzunaslan et al reported that, compared with healthy men, men diagnosed with AS had statistically significant fewer children (1.9 vs 2.5 ) and a higher rate of infertility (9.1 vs $2.9 \%) .{ }^{29}$ These findings could be in part explained by the high incidence of varicocele and sperm abnormalities that have been reported for men diagnosed with AS. ${ }^{6} 3031$ Nonetheless, this study was primarily designed to study the impact of Behçet's syndrome on male fertility and only included 79 male patients diagnosed with AS.
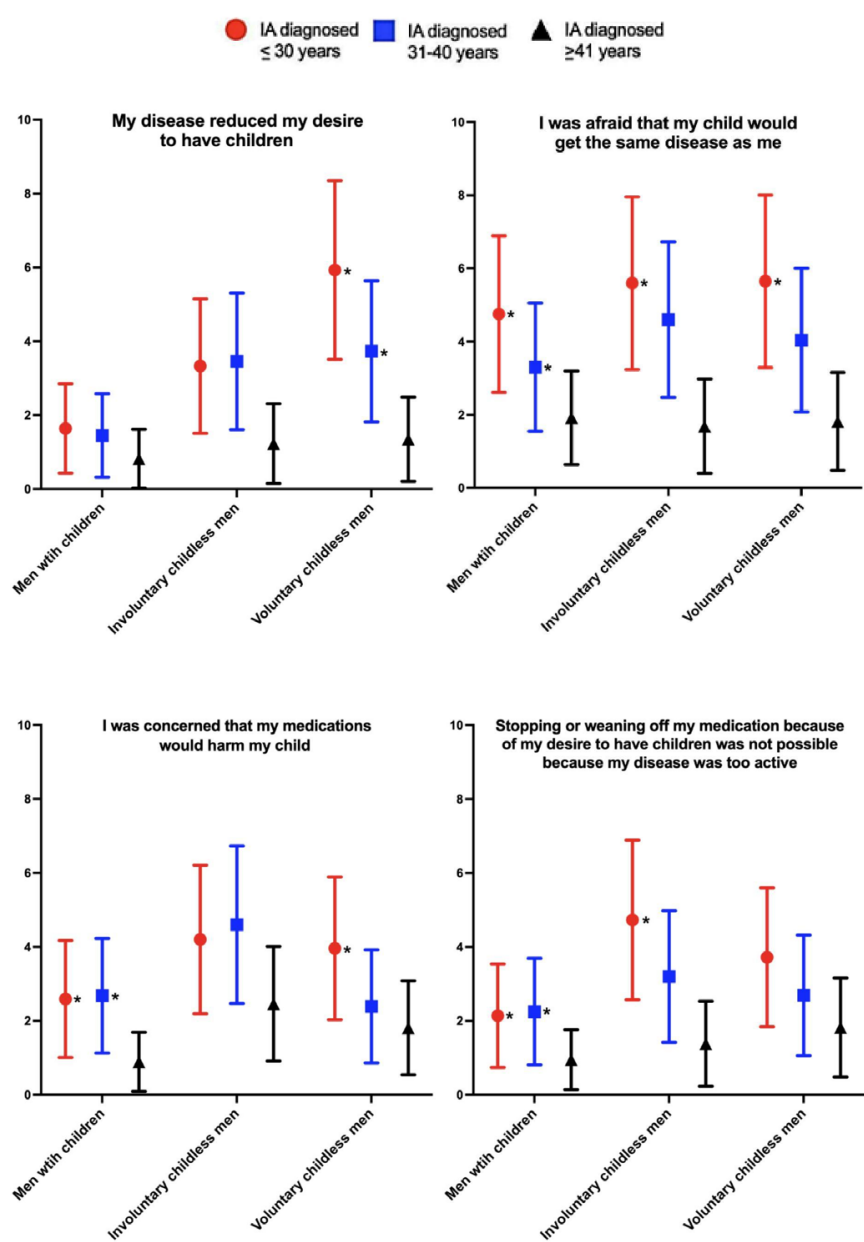

Figure 4 Comparison of the reported impact of la on different aspects of family planning in men with children, involuntary and voluntary childless men. A Likert scale with 0 meaning 'totally disagree' and 10 'totally agree' was used (mean with SD). * $p \leq 0.05$ compared with those diagnosed age $\geq 41$ years. IA, inflammatory arthritis. 
Table 4 Fertility evaluation

\begin{tabular}{|c|c|c|c|c|c|}
\hline & $\begin{array}{l}\text { All patients } \\
(\mathrm{N}=628)\end{array}$ & $\begin{array}{l}\text { IA diagnosed } \\
\leq 30 \text { years } \\
(\mathrm{N}=137)\end{array}$ & $\begin{array}{l}\text { IA diagnosed } \\
31-40 \text { years } \\
(\mathrm{N}=149)\end{array}$ & $\begin{array}{l}\text { IA diagnosed } \\
\geq 41 \text { years } \\
(\mathrm{N}=342)\end{array}$ & $P$ value \\
\hline \multicolumn{6}{|l|}{ Fertility } \\
\hline Female fertility evaluation (partner), $n(\%)$ & $71(15.04)$ & $18(18.56)$ & $24(20.69)$ & 29 (11.42) & 0.069 \\
\hline \multicolumn{6}{|l|}{ Male fertility evaluation outcome } \\
\hline Infertility secondary to unknown cause, n (\%) & $7(1.16)$ & $3(2.26)$ & $3(2.05)$ & $1(0.31)$ & 0.105 \\
\hline \multicolumn{6}{|l|}{ Female fertility evaluation outcome } \\
\hline No female fertility problem identified, $\mathrm{n}(\%)$ & $34(5.41)$ & $8(6.02)$ & $11(7.53)$ & $15(4.59)$ & 0.066 \\
\hline Female infertility secondary to known cause $\ddagger$, n (\%) & $24(3.96)$ & $6(4.51)$ & $9(6.16)$ & $9(2.75)$ & 0.199 \\
\hline Female infertility secondary to unknown cause, $\mathrm{n}(\%)$ & $7(1.16)$ & $4(3.01)^{*}$ & $2(1.37)$ & $1(0.31)$ & 0.047 \\
\hline
\end{tabular}

${ }^{*} P \leq 0.05$ compared with those diagnosed age $\geq 41$ years.

$+P \leq 0.05$ compared with those diagnosed age $\geq 31-40$ years.

‡Endometriosis, fallopian tube obstruction, polycystic ovary syndrome, uterine abnormality, early menopause.

$\mathrm{IA}$, inflammatory arthritis.

Multiple mechanisms can be responsible for our findings. Biological mechanisms, namely inflammation, may contribute to the impaired fertility in men with IA. Several cytokines that are characteristic of the immune response associated with IA, such as tumour necrosis factor (TNF), play important roles in modulating testicular homoeostasis and regulating spermatogenesis. ${ }^{32}$ Increased expression of messenger RNA for interleukin1-beta, TNF and interferon-gamma has been observed in testicular tissue of men with disturbed spermatogenesis. ${ }^{34}$ Correspondingly, inflammation may impair normal reproductive development before or during puberty, or have a direct negative impact on the spermatogenesis during the reproductive age. ${ }^{35-40}$

Beyond inflammation, pharmacological treatment associated with IA can also result in damage to the male reproductive axis. ${ }^{41} 42$ Moreover, side effects such as hypogonadism and low sperm quality have been associated with frequently used immunosuppressive agents. ${ }^{13}$ It has been estimated that among involuntary childless men that present to infertility clinics, $25 \%$ take drugs that have the potential to negatively impact male sexual function and $10 \%$ take drugs associated with male fertility impairment. $^{42}$

Furthermore, several psychosocial factors, associated with a diagnosis of IA, may have contributed to the lower fertility rate as observed in this study. ${ }^{43}$ In our study, due to problems or concerns associated with IA and its treatment and based on medical advice (or the lack of), men with IA and their partners decided to become voluntarily childless or to delay their plans to become parents. These psychosocial factors were of special importance for men diagnosed before the peak of reproductive age. Moreover, some of these psychosocial factors could be associated with psychological comorbidities that are highly prevalent in patients diagnosed with IA such as depression and anxiety. These comorbidities have also been associated with sexual health problems. $^{44-46}$

Our study has several strengths. It is the first large study ( $\geq 600$ participants) specifically designed to detect statistically significant differences in a robust outcome measure (fertility rate). In addition, we used an extensive questionnaire to gain insight into most of the factors that might have influenced our primary outcome measure. Our study has important limitations. First, our response rate was low. However, the response rate is comparable to similar studies that explored male fertility rate in chronic diseases. ${ }^{22}$ Second, men diagnosed with chronic diseases and especially those who use pharmacological therapy are more aware of potential fertility problems ${ }^{47} 48$ and it can be expected that these men are more likely to seek fertility evaluation. Furthermore, men who experience fertility problems might be more willing to participate in these type of studies. Both factors are potential sources of selection bias in our study. In this respect, in the Netherlands, strict healthcare policies and referral guidelines reduce the possibility of self-referrals or unnecessary fertility evaluations. It is also reassuring that the response rates were similar between the three groups of men and that the results from our control group, men diagnosed $\geq 41$ years, were strikingly similar to the data available in the general population further strengthening our comparisons. Lastly, this was a retrospective study. Recently, it has been shown that the sperm quality of male patients diagnosed with AS improved after being treated with TNF- $\alpha$ inhibitors. ${ }^{49}{ }^{50}$ Furthermore, to get approval, new drugs are facing more strict protocols with regard to testicular toxicity. Therefore, the current conditions for men with IA, regarding treatment options and treatment strategies (biological therapy, shared-decision process, treat to target strategies), might be different than they were when our participants were in the peak of their reproductive age.

The results of this study may have several implications. In the clinical setting, rheumatologists should be aware that IA and/or the pharmacological treatment associated with IA may impair male fertility. Accordingly, they should discuss this with their patients, inform them about the impact of IA on male fertility and if indicated, adjust treatment aiming at low disease activity with the safest treatment strategy possible. ${ }^{650}$ For research purposes, basic, translational and epidemiological studies are needed to understand the impact of inflammation, pharmacological treatment and psychosocial factors associated with IA on male fertility. To corroborate our findings and to further describe the magnitude of the impact of IA on male fertility, large prospective studies are strongly recommended.

In conclusion, the diagnosis of IA before or during the peak of reproductive age can result in impaired male fertility. Rheumatologists should be aware of this novel association and approach their patients accordingly. Multiple biological and non-biological mechanisms can be responsible for this 
association and more research is urgently needed to improve the quality of care for men diagnosed with IA and a desire for parenthood.

\section{Author affiliations}

${ }^{1}$ Rheumatology, Erasmus MC, University Medical Center, Rotterdam, The Netherlands ${ }^{2}$ Rheumatology, HagaZiekenhuis, Den Haag, The Netherlands

${ }^{3}$ Rheumatology and Clinical Immunology, Maasstad Ziekenhuis, Rotterdam, The Netherlands

${ }^{4}$ Rheumatology, Albert Schweitzer Hospital, Dordrecht, The Netherlands

${ }^{5}$ Rheumatology, Leiden University Medical Center, Leiden, The Netherlands

${ }^{6}$ Rheumatology, Admiraal De Ruyter Hospital, Goes, The Netherlands

${ }^{7}$ Rheumatology, Reinier de Graaf Gasthuis, Delft, The Netherlands

${ }^{8}$ Rheumatology, Sint Franciscus Vlietland Group, Rotterdam, The Netherlands

Twitter Luis Fernando Perez-Garcia @DrReumatologo

Acknowledgements We extend our gratitude to Ron Buijs, data manager of the department of Rheumatology, Erasmus MC for his invaluable help with regards to technical support, data collection and data management. Additionally we would like to thank Annemarie Kraan-Donker, Ellis Niemantsverdriet and Marieke Holtrop for their important administrative and logistical contributions to the study.

Contributors All authors met the authorship criteria, they had a substantial contribution to the conception or design of the work (LFPG, ER, HTWS, JMH, BPK, RJEMD) or the acquisition (LFPG, ER, RJEMD), analysis (LFPG, HTWS and RJEMD) or interpretation of data for the work (all authors) and were involved in revising a draft of this work, gave final approval of this version to be published, and are accountable for all aspects of the work in ensuring accuracy and integrity.

Funding This work was supported by research grants from the Dutch Arthritis Foundation (ReumaNederland) (project number: 16-3-402), ZonMw (project number 849200009) and Consejo Nacional de Ciencia y Tecnologia (CONACYT) (project number 601574). All are non-profit organizations.

Competing interests LFPG Consultant of: Galapagos, MRK Consultant of: Novartis, Grant/research support from: Novartis, RJEMD Speakers bureau: UCB, Roche, Abbvie, Genzyme, Novartis, Consultant of: Galapagos, Grant/research supportfrom: UCB.

\section{Patient consent for publication Not required.}

Ethics approval This study was reviewed by the ethics review boards of all participating centers in compliance with the Declaration of Helsinki. All patients gave their informed consent. 1. Erasmus MC - Ethics Committee: MEC-2018-1418. 2. Admiraal de Ruyter Hospital - Ethics Committee: ADRZ2019-010 iFAME-Fertility. 3. Franciscus Hospital - Ethics Committee: T-110. 4. Leiden University Medical Center, Reinier de Graaf Hospital, Haga Hospital - Ethics Committee: N19.081. 5. Maasstad Hospital - Ethics Committee: L2020040.

Provenance and peer review Not commissioned; externally peer reviewed.

Data availability statement No data are available.

Supplemental material This content has been supplied by the author(s). It has not been vetted by BMJ Publishing Group Limited (BMJ) and may not have been peer-reviewed. Any opinions or recommendations discussed are solely those of the author(s) and are not endorsed by BMJ. BMJ disclaims all liability and responsibility arising from any reliance placed on the content. Where the content includes any translated material, BMJ does not warrant the accuracy and reliability of the translations (including but not limited to local regulations, clinical guidelines, terminology, drug names and drug dosages), and is not responsible for any error and/or omissions arising from translation and adaptation or otherwise.

Open access This is an open access article distributed in accordance with the Creative Commons Attribution Non Commercial (CC BY-NC 4.0) license, which permits others to distribute, remix, adapt, build upon this work non-commercially, and license their derivative works on different terms, provided the original work is properly cited, appropriate credit is given, any changes made indicated, and the use is non-commercial. See: http://creativecommons.org/licenses/by-nc/4.0/.

\section{ORCID iDs}

Luis Fernando Perez-Garcia http://orcid.org/0000-0002-8958-9493

Robbert J Goekoop http://orcid.org/0000-0002-4589-6731

Marc R Kok http://orcid.org/0000-0003-2394-6926

Hieronymus T W Smeele http://orcid.org/0000-0001-7724-7712

Annette H M van der Helm-van Mil http://orcid.org/0000-0001-8572-1437

\section{REFERENCES}

1 Stolwijk C, van Onna M, Boonen A, et al. Global prevalence of spondyloarthritis: a systematic review and meta-regression analysis. Arthritis Care Res 2016;68:1320-31.
2 Hootman JM, Helmick CG, Barbour KE, et al. Updated projected prevalence of self-reported Doctor-Diagnosed arthritis and Arthritis-Attributable activity limitation among US adults, 2015-2040. Arthritis Rheumatol 2016;68:1582-7.

3 Ackerman IN, Pratt C, Gorelik A, et al. Projected burden of osteoarthritis and rheumatoid arthritis in Australia: a population-level analysis. Arthritis Care Res 2018;70:877-83.

4 van der Woude D, van der Helm-van Mil AHM. Update on the epidemiology, risk factors, and disease outcomes of rheumatoid arthritis. Best Pract Res Clin Rheumatol 2018:32:174-87.

5 Brubaker WD, Li S, Baker LC, et al. Increased risk of autoimmune disorders in infertile men: analysis of US claims data. Andrology 2018;6:94-8.

6 Perez-Garcia LF, Te Winkel B, Carrizales JP, et al. Sexual function and reproduction can be impaired in men with rheumatic diseases: a systematic review. Semin Arthritis Rheum 2020;50:557-73.

7 Perez-Garcia LF, Dolhain RJEM, Vorstenbosch S, et al. The effect of paternal exposure to immunosuppressive drugs on sexual function, reproductive hormones, fertility, pregnancy and offspring outcomes: a systematic review. Hum Reprod Update 2020;26:961-1001.

8 Hammarberg K, Collins V, Holden C, et al. Men's knowledge, attitudes and behaviours relating to fertility. Hum Reprod Update 2017;23:458-80.

9 Bodin M, Plantin L, Elmerstig E. A wonderful experience or a frightening commitment? an exploration of men's reasons to (not) have children. Reprod Biomed Soc Online 2019;9:19-27.

10 Vassard D, Lallemant C, Nyboe Andersen A, et al. A population-based survey on family intentions and fertility awareness in women and men in the United Kingdom and Denmark. Ups J Med Sci 2016:121:244-51.

11 Schoumaker B. Across the world is men's fertility different from that of women? Population \& Societies 2017:548:1-4

12 Schoumaker B. Measuring male fertility rates in developing countries with demographic and health surveys: an assessment of three methods. Demographic Research 2017:36:803-50.

13 Zegers-Hochschild F, Adamson GD, Dyer $S$, et al. The International glossary on infertility and fertility care, 2017. Fertil Steril 2017;108:393-406.

14 Agarwal A, Baskaran S, Parekh N, et al. Male infertility. The Lancet 2021;397:319-33

15 Sato A, Naganuma M, Asakura K, et al. Conception outcomes and opinions about pregnancy for men with inflammatory bowel disease. J Crohns Colitis 2010;4:183-8.

16 Glazer $\mathrm{CH}$, Bonde JP, Eisenberg ML, et al. Male infertility and risk of nonmalignant chronic diseases: a systematic review of the epidemiological evidence. Semin Reprod Med 2017:35:282-90.

17 Smeele HTW, Dolhain RJEM. Current perspectives on fertility, pregnancy and childbirth in patients with rheumatoid arthritis. Semin Arthritis Rheum 2019;49:S32-5.

18 Østensen M. Sexual and reproductive health in rheumatic disease. Nat Rev Rheumatol 2017:13:485-93.

19 de Jong PHP, Dolhain RJEM, Fertility DRJ. Fertility, pregnancy, and lactation in rheumatoid arthritis. Rheum Dis Clin North Am 2017:43:227-37.

20 CBvd S. One in six first-time fathers over 402011. Available: https://www.cbs.nl/en$\mathrm{gb} /$ news/2011/39/one-in-six-first-time-fathers-over-40

21 Thomas FS, Stanford JB, Sanders JN, et al. Development and initial validation of a fertility experiences questionnaire. Reprod Health 2015:12:62.

22 Boyer A, Lobbedez T, Ouethrani M, et al. Paternity in male kidney transplant recipients: a French national survey, the paternal study. BMC Nephrol 2020;21:483.

23 Brouwer J, Fleurbaaij R, Hazes JMW, et al. Subfertility in women with rheumatoid arthritis and the outcome of fertility assessments. Arthritis Care Res 2017;69:1142-9.

24 Eudy AM, McDaniel G, Clowse ME. Pregnancy outcomes, fertility, and family planning in women with psoriatic arthritis. Obstet Med 2020;13:70-5.

25 CBvd S. More childless men, 2010. Available: https://www.cbs.nl/en-gb/news/2010/ 27/more-childless-men

26 Ideal and actual number of children [Internet], 2016. Available: http://www.oecd.org/ els/family/database.htm

27 Lechner L, Bolman C, van Dalen A. Definite involuntary childlessness: associations between coping, social support and psychological distress. Hum Reprod 2007;22:288-94.

28 Kumar N, Singh AK. Trends of male factor infertility, an important cause of infertility: a review of literature. J Hum Reprod Sci 2015;8:191-6.

29 Uzunaslan D, Saygin C, Hatemi G, et al. No appreciable decrease in fertility in Behçet's syndrome. Rheumatology 2014;53:828-33.

30 Nukumizu LA, Gonçalves Saad C, Ostensen M, et al. Gonadal function in male patients with ankylosing spondylitis. Scand J Rheumatol 2012;41:476-81.

31 Ozgocmen S, Kocakoc E, Kiris A, et al. Incidence of varicoceles in patients with ankylosing spondylitis evaluated by physical examination and color duplex sonography. Urology 2002;59:919-22.

32 Hedger MP, Meinhardt A. Cytokines and the immune-testicular axis. J Reprod Immunol 2003:58:1-26

33 Ware CF. The TNF receptor super family in immune regulation. Immunol Rev 2011;244:5-8

34 Klein B, Haggeney T, Fietz D, et al. Specific immune cell and cytokine characteristics of human testicular germ cell neoplasia. Hum Reprod 2016;31:2192-202. 
35 Fijak M, Pilatz A, Hedger MP, et al. Infectious, inflammatory and 'autoimmune' male factor infertility: how do rodent models inform clinical practice? Hum Reprod Update 2018;24:416-41.

36 Agarwal A, Rana M, Qiu E, et al. Role of oxidative stress, infection and inflammation in male infertility. Andrologia 2018;50:e13126.

37 Bachir BG, Jarvi K, Infectious JK. Infectious, inflammatory, and immunologic conditions resulting in male infertility. Urol Clin North Am 2014;41:67-81.

38 Nistal M, Paniagua R. Non-Neoplastic diseases of the testis. Urologic Surgical Pathology 2008:614-755.

39 Silva CA, Cocuzza M, Carvalho JF, et al. Diagnosis and classification of autoimmune orchitis. Autoimmun Rev 2014;13:431-4.

40 Chan PTK, Schlegel PN. Inflammatory conditions of the male excurrent ductal system. Part I. J Androl 2002;23:453-60.

41 Sasaki JC, Chapin RE, Hall DG, et al. Incidence and nature of testicular toxicity findings in pharmaceutical development. Birth Defects Res B Dev Reprod Toxicol 2011;92:511-25.

42 Pompe SV, Strobach D, Stief CG, et al. Drug use among men with unfulfilled wish to father children: a retrospective analysis and discussion of specific drug classes. Pharmacoepidemiol Drug Saf 2016;25:668-77.

43 Buhr P, Huinink J. Why Childless men and women give up on having children. Eur J Popul 2017;33:585-606.
44 Perez-Garcia LF, Röder E, Pastoor $H$, et al. It is not just about the sex: viewpoints of dutch adult men with inflammatory arthritis regarding the impact of the disease on their sexual health. Ann Rheum Dis 2021:80:186.

45 Hill J, Bird $H$, Thorpe R. Effects of rheumatoid arthritis on sexual activity and relationships. Rheumatology 2003;42:280-6.

46 Kraaimaat FW, Bakker AH, Janssen E, et al. Intrusiveness of rheumatoid arthritis on sexuality in male and female patients living with a spouse. Arthritis Care Res 1996;9:120-5.

47 Tielemans E, Burdorf A, te Velde E, et al. Sources of bias in studies among infertility clients. Am J Epidemiol 2002;156:86-92.

48 Pedro J, Brandão T, Schmidt L, et al. What do people know about fertility? A systematic review on fertility awareness and its associated factors. Ups J Med Sci 2018;123:71-81.

49 Villiger PM, Caliezi G, Cottin V, et al. Effects of TNF antagonists on sperm characteristics in patients with spondyloarthritis. Ann Rheum Dis 2010;69:1842-4.

50 Ramonda R, Foresta C, Ortolan A, et al. Influence of tumor necrosis factor $\alpha$ inhibitors on testicular function and semen in spondyloarthritis patients. Fertil Steril 2014; 101:1058:359-65. 